\title{
National Childhood Cancer Foundation
}

National Cancer Institute

\section{Source}

National Cancer Institute. National Childhood Cancer Foundation. NCI Thesaurus. Code C39469.

The National Childhood Cancer Foundation is a non-profit organization that serves as the fund-raising foundation, grantee organization, and the fiscal agent for the Children Oncology Group. The Foundation conducts its fundraising and advocacy efforts on behalf of $90 \%$ of the children with cancer in North America, receiving federal and non-federal grants and awards to distribute to the member-institutions. Advocacy and public awareness are also parts of the mission of the Foundation. 